15 Ward BG, Cruickshank DJ, Tucker DF, Love S. Independent expression in serum of three tumour-associated antigens: CA 125, placental alkaline phosphatase and HMFG2 in ovarian carcinoma $\mathrm{Br} \%$ Obstet Gymacol 1987;94:696-8.

16 Schwartz PE, Chambers SK, Chambers JT, Gutmann J, Katopodis N, Foemmel R. Circulating tumor markers in the monitoring of gynecologic malignancies. Cancer 1987;60:353-61.

17 Cole LA, Nam J-H, Chambers JT, Schwartz PE. Urinary gonadotrophin fragment, a new tumor marker. II. Differentiating a benign from malignant pelvic mass. Gynecol Oncol 1990;36:391-4.

18 Kacinski BM, Chambers SK, Carter D, Filderman AE, Stanley ER. The macrophage colony stimulating factor CSF-1, an auto- and paracrine tumour cytokine is also a circulating 'tumor marker' in patients with ovarian, endometrial and pulmonary neoplasms. In: Dinarello CA, Kluger M],
Powanda MC, Oppenheim JJ, eds. The physiological and pathological effects of cytokines. New York: Wiley-Liss, 1990:393-400.

19 Jacobs IJ, Oram DH, Bast RC Jr. Strategies for improving the specificity of screening for ovarian cancer with tumor associated antigens CA 125 , CA 15-3, and TAG 72.3. Obstet Gynecol 1992;80:396-9.

20 Zurawski VR, Sjovall K, Schoenfeld DA, Broderick SF, Hall P, Bast RC Jr et al. Prospective evaluation of serum CA 125 levels in a normal population, et al. Prospective evaluation of serum CA 125 levels in a normal population, ovarian cancer. Gynecol Oncol 1990;36:299-305.

21 Narod SA, Feunteun J, Lynch HT. Familial breast-ovarian cancer locus on chromosome 17q12-q23. Lancet 1991;338:82-3.

(Accepted 2 March 1993)

\title{
Serevent nationwide surveillance study: comparison of salmeterol with salbutamol in asthmatic patients who require regular bronchodilator treatment
}

Win Castle, Rick Fuller, John Hall, James Palmer

Abstract

Objective-To compare safety of salmeterol and salbutamol in treating asthma.

Design-Double blind, randomised clinical trial in parallel groups over 16 weeks.

Setting-General practices throughout the United Kingdom.

Subjects -25180 patients with asthma considered to require regular treatment with bronchodilators who were recruited by their general practitioner $(\mathbf{n}=3516)$.

Interventions-Salmeterol (Serevent) $\quad(50 \mu g$ twice daily) or salbutamol ( $200 \mu \mathrm{g}$ four times a day) randomised in the ratio of two patients taking salmeterol to one taking salbutamol. All other drugs including prophylaxis against asthma were continued throughout the study.

Main outcome measures-All serious events and reasons for withdrawals (medical and non-medical) whether or not they were considered to be related to the drugs.

Results-Fewer medical withdrawals due to asthma occurred in patients taking salmeterol than in those taking salbutamol $\left(2.91 \% v 3.79 \% ; \chi^{2}=13.6\right.$, $p=0 \cdot 0002)$. Mortality and admissions to hospital were as expected. There was a small but nonsignificant excess mortality in the group taking salmeterol and a significant excess of asthma events including deaths in patients with severe asthma on entry. Use of more than two canisters of bronchodilator a month was particularly associated with the occurrence of an adverse asthma event.

Conclusions-Treatment over 16 weeks with Glaxo Group Research Greenford, Middlese UB6 0HE

Win Castle, director of international drug surveillance Rick Fuller, director of respiratory medicine

Allen and Hanbury's, Uxbridge, Middlesex UB11 1BT

John Hall, medical director

Glaxo Research Institute, Research Triangle Park, North Carolina, United States

James Palmer, vice president of clinical research

Correspondence to: Dr Fuller. the control of asthma may be worse during treatm with regular fenoterol compared with intermittent $\beta$ agonists. ${ }^{4}$ More recently the safety of $\beta$ agonists has come under scrutiny. ${ }^{5}$ Firstly, a rebound increase in bronchial reactivity has been observed in research that studied regular use of $\beta$ agonists, ${ }^{6}$ although this has not been a consistent finding. ${ }^{7}$ Secondly, a reduction in lung function was reported during a two year study of salbutamol and ipratropium bromide, ${ }^{8}$ although again this has not been found in other studies. ${ }^{9}$

In addition, epidemiological studies have shown an increase in deaths due to asthma, which some authors have related to the use of $\beta$ agonists, ${ }^{10}$ and a more detailed case control study has related increased use of $\beta$ agonists to an increased risk of death from asthma." For each additional canister administered each month the odds ratio increased by $2 \cdot 6$. Causal relations have been suggested but the high use of $\beta$ agonists probably merely reflects severity of asthma and that these patients with more severe asthma are at greater risk of death. Such a relation between severe asthma and the risk of death has indeed been shown in other epidemiological studies. ${ }^{12}$

The development of a long acting $\beta$ agonist $^{13}$ for which regular use is recommended has raised some concerns. Our study compared the safety of salmeterol ( $50 \mu \mathrm{g}$ Serevent twice daily) with that of salbutamol (200 $\mu \mathrm{g}$ four times a day) in a large number of patients with asthma $(>25000)$. Because of the large numbers we could compare our results with events related to asthma throughout the United Kingdom..$^{14} 15$

\section{Subjects and methods}

PROTOCOL

The trial was a randomised, double blind study in parallel groups over 16 weeks. Randomisation from blocks of six was four patients allocated to salmeterol $(50 \mu \mathrm{g}$, two puffs morning and bedtime and two puffs of placebo noon and early evening to retain the blinding) to two patients allocated to salbutamol $(200 \mu \mathrm{g}$, two puffs four times a day). The general practitioners were all given prenumbered treatment packs which they gave to the patients as they were allocated the next consecutive study number. All other drugs including prophylaxis against asthma was continued throughout the study. The supervising general practitioner was asked to prescribe whatever treatment he or she considered appropriate to relieve symptoms. The trial was conducted by 3516 general practitioners and monitored by staff employed by the medical department of Allen and Hanburys.

\section{PATIENTS}

At the first visit of the study patients with asthma were recruited by their general practitioner and randomised. After they had shown effective use of an 
inhaler they then started the treatment. There was no run in period. Patients had to be over the age of 12 years and have a clinical requirement for regular bronchodilator treatment. Patients taking $\beta$ blockers were excluded as were patients with serious uncontrolled pulmonary or systemic disease or who were pregnant. The general practitioner completed a demographic questionnaire with details of each patient's present drugs, medical history, etc. The general practitioner also clinically assessed each patient as having mild, moderate, or severe asthma.

The patient returned after four, eight, and 16 weeks of the study treatment, and the investigator was instructed to check for the occurrence of serious adverse events whether or not they were considered to be related to the drug and to record these as well as reason for withdrawals (medical or non-medical) on a serious adverse event or withdrawal form. The general practitioners were reimbursed $£ 50$ for each completed patient studied.

\section{DATA MANAGEMENT METHODS}

A serious adverse event was defined in the protocol as death from any cause, any event requiring admission to hospital or prolonging a stay in hospital, a life threatening event, a severely disabling or incapacitating event, a congenital abnormality, cancer, or drug overdose. On completing a serious adverse event or withdrawal form the investigator was required to add his or her assessment of causal relation to the study drug. The options were definitely related, probably related, probably unrelated, or definitely unrelated.

Any patient could be withdrawn from the study at any time at the discretion of the investigator or the request of the patient, but the reason for doing so was required for each case. Whenever a patient was withdrawn from the study the investigator had to confirm that the patient remained alive at the end of the study.

Each serious adverse event or withdrawal form was forwarded promptly to the medical department, where its receipt was documented but the code not broken. The investigator was contacted by telephone or letter or visited if follow up information was required. Documentation from death certificates and postmortem examinations was obtained. The records were photocopied and sent to the international drug surveillance division of Glaxo Group Research, where the randomisation code was broken and the drug identity was recorded on the form. Access to the code was restricted to the people within the division who required the information to generate interim reports to regulatory authorities.

Individual reports of adverse events which were considered serious under the requirements of the regulatory authorities and also assessed by the investigator as definitely or probably related to the study drug were forwarded immediately to the Medicines Control Agency in the United Kingdom and, after prior agreements, periodically to the Food and Drug Administration in the United States. Interim confidential reports were also regularly prepared for the two organisations, as well as for other regulatory authorities as requested.

For the purpose of providing overview tables, the type of report for each patient was classified as death, serious events, or withdrawals. Each death was categorised as respiratory and related to asthma; chronic obstructive airways disease; respiratory but not related to asthma, including lung cancer; cardiovascular or relating to other body systems. Two respiratory physicians employed by Glaxo reviewed all possible respiratory deaths to give their view about the most appropriate medical category without knowing to which drug the patient had been randomised.
For patients with adverse events falling into more than one category, deaths were given precedence over events meeting the regulatory definitions of serious, which in turn took precedence over withdrawals for minor medical reasons. If follow up information was received about a particular patient which materially altered the nature of the case or the outcome-for example, if a patient with a serious adverse event was later found to have died within the study period - this record on the database was updated to reflect the new information.

Events related to asthma were taken to include all asthmatic events irrespective of causality. Chest infections such as pneumonia, when no symptom of bronchospasm was reported, were categorised as respiratory but not related to asthma. Respiratory adverse events were defined according to ICD (ninth revision).

When patients were described as having an event in which different symptoms or diagnoses fell into different body systems, asthma as a cause was given precedence. Otherwise the event was counted against the classification of the body system of the most important symptom in the opinion of Glaxo physicians.

An independent review of the blinded data for deaths related or possibly related to asthma in both treatment groups was undertaken by three consultants selected by the National Asthma Campaign. An independent statistician received a copy of the interim tables forwarded to the regulatory authorities and gave independent statistical advice throughout. The standard (demographic) forms completed at entry and at four, eight, and 16 weeks were contracted out for data management and analysis by VAMP Research Ltd. Comparisons between the treatment groups were made by $\chi^{2}$ test. The results are expressed as absolute incidence and relative risk between treatments. No formal power calculation on any specific event was made as the primary objective was to compare the incidence of all safety outcomes. The numbers in table I refer to the number of patients in whom full data were available. The larger numbers in table III refer to the total numbers randomised.

\section{Results}

There were 25180 patients randomised to treatment, 16787 to salmeterol and 8393 to salbutamol. All serious adverse event or withdrawal forms were entered and analysed. Randomised treatment groups according to entry criteria (table I) were well balanced

TABLE I-Criteria on entry of patients with asthma randomised to salmeterol or salbutamol. Values are numbers (percentages)

\begin{tabular}{lrr}
\hline Entry criteria & $\begin{array}{r}\text { Salmeterol } \\
(\mathrm{n}=14113)\end{array}$ & $\begin{array}{r}\text { Salbutamol } \\
(\mathrm{n}=7082)\end{array}$ \\
\hline Men & $6970(49)$ & $3509(50)$ \\
Age (years): & & \\
$<18$ & $899(6 \cdot 4)$ & $421(5 \cdot 9)$ \\
$18-30$ & $2752(19)$ & $1359(19)$ \\
$31-40$ & $1970(14)$ & $1095(16)$ \\
$41-50$ & $2064(15)$ & $1060(15)$ \\
$51-60$ & $2435(17)$ & $1200(17)$ \\
$>60$ & $3993(28)$ & $1947(28)$ \\
General practitioner's classification of severity & & \\
$\quad$ of asthma: & & \\
Mild & $2386(17)$ & $1235(17)$ \\
Moderate & $9261(66)$ & $4592(65)$ \\
Severe & $2466(17)$ & $1255(18)$ \\
Drugs for asthma taken & & \\
Oral corticosteroids & $679(4 \cdot 8)$ & $332(4 \cdot 7)$ \\
Inhaled corticosteroids & $9809(69)$ & $4895(69)$ \\
Methylxanthines & $2157(15)$ & $1055(15)$ \\
$\beta$ Agonists (oral) & $688(4 \cdot 9)$ & $377(5 \cdot 3)$ \\
$\beta$ Agonists (inhaled) & $12820(91)$ & $6415(91)$ \\
$\beta$ Agonists (nebulised) & $187(1 \cdot 3)$ & $107(1 \cdot 5)$ \\
Sodium cromoglycate/nedocromil/ketotifen & $618(4 \cdot 4)$ & $269(3 \cdot 8)$ \\
Anticholinergic drugs & $780(5 \cdot 5)$ & $370(5 \cdot 2)$ \\
Combination drugs & $1036(7 \cdot 3)$ & $475(6 \cdot 7)$ \\
\hline
\end{tabular}

^Many patients were taking more than one drug at entry. 
at entry for demography, severity of asthma, drug treatment, and concomitant diseases. Sixty nine per cent were taking inhaled steroids, $4.7 \%$ oral steroids, and $9.7 \%$ had used three or more canisters of $\beta$ agonist inhalers in the four weeks before recruitment (table II).

The requirement for the use of $\beta$ agonists was related to the severity of asthma, with the number of cans per month being 1.2 for mild asthma, 1.5 for moderate, and 2.0 for severe in both groups. Of the subjects considered to be mildly asthmatic $1 \cdot 2 \%$ were taking oral and $45 \%$ inhaled steroids; the figures were $3 \%$ and $72 \%$ in those with moderate asthma and $15 \%$ and $83 \%$ in those with severe asthma.

TABLE II-Use of $\beta$ agonist inhalers in four weeks before study in patients ${ }^{*}$ with asthma randomised to salmeterol or salbutamol. Values are proportions (fercentages)

\begin{tabular}{|c|c|c|}
\hline Use of inhalers & Salmeterol & Salbutamol \\
\hline $\begin{array}{l}\text { Average number of inhalers } \\
\text { used in previous fo... }\end{array}$ & $1.57(n=12.238)$ & $1.58(n=6123)$ \\
\hline $\begin{array}{c}\text { Number Ehater a } \\
\text { proustor: }\end{array}$ & & \\
\hline 0 & 22 & $16^{n-5}$ \\
\hline $1-2$ & $1077.216(887)$ & $5303 / 6070(88 \cdot 3)$ \\
\hline$\geqslant 3$ & $1: 53 / 12149(9 \cdot 5)$ & $599 / 6070(9 \cdot 9)$ \\
\hline \multicolumn{3}{|l|}{ Number of inhalations/day: } \\
\hline $0-8$ & $11576 / 12122(95 \cdot 5)$ & $5798 / 6071(95 \cdot 5)$ \\
\hline $9-20$ & $526 / 12122(4 \cdot 3)$ & $263 / 6071(4 \cdot 3)$ \\
\hline$\geqslant 21$ & $20 / 12122(0 \cdot 16)$ & $10 / 6071(0 \cdot 16)$ \\
\hline
\end{tabular}

*Patients with data missing from case record forms omitted.

TABLE III-Deaths, serious events, and withdrawals in patients with aithma randomised to salmeterol or salbutamol. Values are numbers (percentages)

\begin{tabular}{|c|c|c|c|c|}
\hline Outcome & $\begin{array}{l}\text { Salmeterol } \\
(n=16787)\end{array}$ & $\begin{array}{l}\text { Salbutamol } \\
(\mathrm{n}=8393)\end{array}$ & $\begin{array}{l}\text { Relative } \\
\text { risk }\end{array}$ & Significance \\
\hline \multicolumn{5}{|l|}{ Deaths: } \\
\hline Respiratory and related to asthma & $12(0 \cdot 07)$ & $2(0 \cdot 02)$ & $3 \cdot 00$ & ${ }^{\star} \mathrm{p}=0.105$ \\
\hline Other obstructive airways disease & $4(0.02)$ & $1(0.01)$ & $2 \cdot 00$ & ${ }^{\star} \mathrm{p}=0.506$ \\
\hline Other respiratory causes & $2(0.01)$ & $1(0.01)$ & 1.00 & ${ }^{\star} \mathrm{p}=1.000$ \\
\hline Cardiovascular & $29(0.17)$ & $10(0 \cdot 12)$ & 1.45 & $x^{i}=1.0, \quad p=0.308$ \\
\hline All other causes & $6(0 \cdot 04)$ & $6(0.07)$ & $0 \cdot 50$ & $x^{2}=1 \cdot 5, \quad p=0.221$ \\
\hline Not known & $1(<0.01)$ & $0(0)$ & & $\star p=1.000$ \\
\hline Subtotal & $54(0 \cdot 32)$ & $20(0 \cdot 24)$ & 135 & $x^{i}=13, \mathrm{p}=0.250$ \\
\hline \multicolumn{5}{|l|}{ Admission to hospital/life threatening: } \\
\hline Respiratory and related to asthma & $193(1 \cdot 15)$ & $102(1 \cdot 22)$ & 0.95 & $\chi^{2}=0.2, \quad p=0.651$ \\
\hline Respiratory but not related to asthma & $12(0 \cdot 07)$ & $7(0 \cdot 08)$ & 0.86 & $\chi=0.1, \quad p=0.746$ \\
\hline Non-respiratory & $112(0.67)$ & $57(0.68)$ & 0.98 & $x=0.0, \quad p=0.913$ \\
\hline Subtotal & $317(1.89)$ & $106(1.97)$ & 0.95 & $\chi^{2}=0.2, \quad p=0.629$ \\
\hline \multicolumn{5}{|l|}{ Other serious events: } \\
\hline Respiratory and related to asthma & $198(: \cdot 18)$ & $100(1 \cdot 19)$ & 0.99 & $\chi^{2}=0.0, \quad p=0.935$ \\
\hline Respiratory but not related to asthma & $22(0.13)$ & $16(0 \cdot 19)$ & 0.69 & $\chi=1.3, \quad p=0.251$ \\
\hline Non-respiratory & $131(0 \cdot 78)$ & $.0(0.71)$ & 1.09 & $\chi^{2}=0.3, \quad p=0.574$ \\
\hline Subtotal & $351(2.09)$ & 1., 2.091 & $1 \cdot 00$ & $\chi=0.0, \quad p=0.975$ \\
\hline \multicolumn{5}{|l|}{ Other withdrawals: } \\
\hline Respiratory and related to asthma & $488(2.91)$ & $318(3 \cdot 79)$ & 0.77 & $\chi^{2}=13 \cdot 6, p=0.0002$ \\
\hline Respiratory but not related to asthma & $121(0 \cdot 72)$ & $50(060)$ & $1 \cdot 21$ & $\chi^{2}=1.3, \quad p=0.256$ \\
\hline Non-respiratory & $785(4 \cdot 67)$ & $380(4.53)$ & 1.03 & $\chi^{2}=0.3, \quad p=0.605$ \\
\hline Subtotal & $1394(8 \cdot 30)$ & $748(8.9 \mathrm{i})$ & 0.93 & $x=2 \cdot 4, \quad p=0.119$ \\
\hline Non-medical withdrawals & $2156(12 \cdot 84)$ & $1100(13 \cdot 11)$ & 0.98 & $x^{\prime}=0.3, \quad p=0.586$ \\
\hline Total & $4272(25 \cdot 48)$ & $2209(26 \cdot 32)$ & 0.97 & $\chi=1 \cdot 6, \quad p=0 \cdot 200$ \\
\hline
\end{tabular}

^Probability of obtaining as extreme or more extreme a differ,..
Table III summarises all deaths, serious events, and withdrawals, whose incidences were similar between the two groups. The only significant difference was the numbers of medical withdrawals due to asthma, which were fewer with salmeterol than with salbutamol $\left(2.91 \%\right.$ v $\left.3.79 \%, \chi^{2}=13.6 ; p=0.0002\right)$.

For salmeterol there were 12 deaths from asthma out of 16787 patients treated $(0.07 \%)$ and for salbutamol two out of $8393(0.02 \%)$. When summation of binominal probabilities was performed and the 2:1 randomisation accounted for the $95 \%$ confidence interval for the relative risk of 3.0 between the two groups was $0 \cdot 7$ to 20 . The difference between the two groups $(0.07 \% v 0.02 \%)$ was not significant $(p=0 \cdot 105)$. Obviously the relative risk of 2.0 and 1.0 for other obstructive airways disease and other non-obstructive airways disease respectively are similarly not significantly different, the probability being 0.506 and 1.0 of obtaining a distribution as extreme or more extreme in either direction by chance.

The 14 deaths from asthma were in patients with severe asthma either in the view of the general practitioner or in the view of the independent consultants appointed by the National Asthma Campaign. Five were taking oral steroids and a further patient was taking nebulised $\beta$ agonists. Another patient had had previous attacks described as catastrophic, but in this case inhaled steroids were stopped because of fear of growth suppression. All but two of the patients who died were taking two or more inhalers of $\beta$ agonist a month at the time of entry to the study. For 10 of the patients who died the independent consultants considered that their asthma could possibly have been more appropriately treated by earlier or higher doses of glucocorticosteroids. Five of the patients who died had been admitted to hospital.

The overall incidence of serious events from all causes (table III) $(4 \cdot 0 \%$ for salmeterol $v 4 \cdot 1 \%$ for salbutamol) was unremarkable, the incidence of those suspected as being related to the drugs $(1 \cdot 19 \% v$ $1 \cdot 15 \%$ ) was low, and importantly there was no evidence of any previously unrecognised side effect of salmeterol or salbutamol. Not surprisingly in a study of this type there was a fairly high rate of patients withdrawing for non-medical reasons, which was balanced between the two groups (table III).

Table IV shows non-fatal events related to asthma by randomised treatment group and also by the estimated rates of these non-fatal events according to classification of severity of asthma before treatment. For each indicator of severity (general practitioner's assessment, oral steroids, and increase of $\beta$ agonist inhalers used in the previous four weeks) there was a consistent significant increase in rates of events related to asthma

TABLE IV-Non-fain toent related to astiria : patients with asthma randomised to salmeterol or salbutamol

\begin{tabular}{|c|c|c|c|c|}
\hline \multirow[b]{2}{*}{ Indicator of severity } & \multicolumn{2}{|c|}{ Salmeterol } & \multicolumn{2}{|c|}{ Salbutamol } \\
\hline & $\begin{array}{l}\text { No }(\%) \text { in total } \\
\text { group on } \\
\text { entry }\end{array}$ & $\begin{array}{c}\text { No }(\%)^{\star} \text { with non-fatal } \\
\text { events } \\
(n=879)\end{array}$ & $\begin{array}{l}\text { No (\%) in total } \\
\text { group on } \\
\text { entry }\end{array}$ & $\begin{array}{c}\text { No }(\%)^{\star} \text { with non-fatal } \\
\text { events } \\
(n=520)\end{array}$ \\
\hline \multicolumn{5}{|c|}{ Classification by general practitioner: } \\
\hline Mild & $2386(17 \cdot 1)$ & $101(3 \cdot 5)$ & $1235(17 \cdot 4)$ & $66(4 \cdot 6)$ \\
\hline Moderate & $9261(65 \cdot 4)$ & $482(4 \cdot 4)$ & $4592(64.8)$ & $277(5.0)$ \\
\hline Severe & $2466(17 \cdot 6)$ & $291(9.9)$ & $1255(17 \cdot 7)$ & $171(11 \cdot 6)$ \\
\hline Unknown & & $\begin{array}{l}5 \\
x^{2}(\text { trend })=121, p<0.001\end{array}$ & & $\begin{array}{l}6 \\
\left.y^{2} \text { (trend }\right)=63,0<0.001\end{array}$ \\
\hline \multicolumn{5}{|l|}{ Oral steroids: } \\
\hline Taking oral steroids & $679(4 \cdot 8)$ & $80(10 \cdot 0)$ & $332(4 \cdot 7)$ & $59(14 \cdot 8)$ \\
\hline Other (assumed not) & $13434(95 \cdot 2)$ & $799(5 \cdot 0)$ & $6750(95 \cdot 3)$ & $461(5 \cdot 8)$ \\
\hline Unknown & & $\begin{array}{c}0 \\
y^{2}=38,0<0.001\end{array}$ & & $\begin{array}{c}0 \\
x^{2}=53.0<0.001\end{array}$ \\
\hline \multicolumn{5}{|c|}{$\begin{array}{l}\text { No of } \beta \text { agonist inhalers used in previous four } \\
\text { weeks: }\end{array}$} \\
\hline 0 & $220(1 \cdot 8)$ & 0 & $108(1 \cdot 8)$ & 0 \\
\hline $1-2$ & $10776(88 \cdot 6)$ & $613(4 \cdot 1)$ & $5363(88.3)$ & $365(4.9)$ \\
\hline $3+$ & $1153(9 \cdot 6)$ & $117(7 \cdot 2)$ & $599(9 \cdot 9)$ & $67(8 \cdot 3)$ \\
\hline Unknown & & $\begin{array}{c}149 \\
\left.\chi^{2} \text { (trend }\right)=47, p<0.001\end{array}$ & & $\begin{array}{c}88 \\
\left.\chi^{2} \text { (trend }\right)=25, p<0.001\end{array}$ \\
\hline
\end{tabular}

^Estimated rate of non-fatal events related to asthma according to classification of severity of asthma before treatment. 
with severity within each randomised treatment group $(p<0.001)$. The difference in rates of events between salmeterol and salbutamol was assessed by using a Mantel-Haenszel test, stratified by each of the three indicators of severity of asthma at entry in turn. For each, there was a significantly lower rate in patients treated with salmeterol than with salbutamol as follows: general practitioner's classification $\chi^{2}=9 \cdot 15(p=0.002)$, oral steroid use $\chi^{2}=9.86(p=0.002)$, and inhaler use $\chi^{2}=8 \cdot 13(p=0 \cdot 004)$.

\section{Discussion}

This trial is the largest randomised, double blind clinical trial ever conducted in the United Kingdom. The aim was to recruit about 24000 patients: 16000 to salmeterol and 8000 to salbutamol. Recruitment started in late 1990 and finished during early December 1991. Waller et al recently criticised surveillance studies sponsored by pharmaceutical companies on the grounds that they did not include comparator groups, that recruitment was slow (so slow in some that the study had to be abandoned), that the total numbers of patients were low compared with the median of 1480 patients presented in original product licence applications, and finally that companies were slow to provide study results. ${ }^{16} \mathrm{We}$ believe this trial had none of these failings. About 16 times the median number in product licence applications were recruited in 14 months. Glaxo reported monthly to the Medicines Control Agency, and the final safety report was sent to the agency within four weeks after the last recruited patient had completed the 16 week study. Inevitably the amount of detail in such a vast study and its overall quality is of a lower standard than that usually obtained from smaller well controlled preregistration studies conducted to good clinical practice.

Comparison of the reported events shows that the only significant differences were the number of medical withdrawals due to asthma, fewer occurring with salmeterol $(2.91 \% v 3.79 \%)$. The relative benefits of treatment can be inferred to some degree from the rate of withdrawal. None of the other events in this trial approached differences which were significant, the study being sized appropriately and of adequate duration to detect a clinically meaningful difference.

There was a numerical excess of deaths in the salmeterol group: $0.07 \%$ compared with $0.02 \%$, a relative risk of 3 . The numbers were very small, however, and the confidence interval of this risk was wide; the difference was therefore not significant. Is the difference then a chance finding? Obviously we cannot answer this, although a number of points need to be considered. The overall number of deaths (14) is in line with that which would have been expected of a sample of patients with asthma of this size in the United Kingdom - that is, $15 . .^{14}$ This comparison would be valid only if the distribution of severe asthma in the study population was at least as great as that in the general population. The patients recruited to the study did not predominantly have mild asthma; $17 \%$ were classified by their general practitioners as having severe asthma at entry, $69 \%$ were taking inhaled steroids, $4.7 \%$ were taking oral steroids, $9.5 \%$ had used three or more canisters of $\beta$ agonist inhalers during the four weeks before the study, and, of course, all had a clinical requirement for regular bronchodilator treatment. As a comparison, in $199052 \%$ of adults with asthma were issued with at least one prescription for an inhaled steroid, $3 \%$ were given oral steroids for a full 12 months as maintenance treatment $(5 \cdot 1 \%$ at some time during the year), and $3.4 \%$ were issued with three or more $\beta$ agonist inhalers each month (AAH Meditel UK, unpublished data). Therefore the mortality was not biased because the study recruited patients with mild asthma. In addition, there was no detectable pattern in the deaths related to asthma which occurred in patients deemed by the independent assessors to have severe asthma. Also other events related to asthma showed no trend towards being worse with salmeterol than salbutamol. In fact, the only significant difference in the entire study was the opposite.

Previous much smaller studies such as those described by Sears $e t a t^{4}$ and van Schayck et $a l^{\beta}$ described an apparent deterioration in asthma, albeit over a longer treatment period. Our data are not consistent with this as the overall rates of death and admission to hospital were not excessive, and patients with mild and moderate asthma were not put at equal risk by the use of the $\beta$ agonist as were those with severe asthma. The problem of deaths from asthma and severe events is therefore one of undertreatment of asthma rather than regular use of $\beta$ agonists. As the independent reviewers suggested that the asthma might have been more appropriately treated by earlier or higher doses of glucocorticosteroids in at least 10 of the patients in the study who died, it is appropriate to strengthen the recommendations of how best to treat severe asthma. Glaxo has therefore altered all its data sheets for drugs used to treat asthma, both $\beta$ agonists and inhaled corticosteroids, to improve the information to doctors on the treatment of the disease, especially when it is severe or unstable. This study clearly indicates such patients are at risk.

We suggest that patients with severe and/or unstable asthma are at potential risk of dying from the disease. Use of high doses (two or more canisters a month) of $\beta$ agonists is not appropriate as the main or only treatment and is related to severity of disease. Such patients require stabilisation of their asthma with appropriate doses of inhaled or oral glucocorticosteroids $(>1 \mathrm{mg}$ per day of beclomethasone dipropionate or equivalent) as their main treatment.

We thank Sir David Cox FRS, who received a copy of the interim tables forwarded to the regulatory authorities and gave independent statistical advice throughout, and also the National Asthma Council and the three consultants it selected: Drs Martyn Partridge, Martin Hetzel, and Brian Harrison

1 British Thoracic Society, Research Unit of the Royal College of Physicians of London, King's Fund Centre, National Asthma Campaign. Guidelines for management of asthma in adults. I. Chronic persistent asthma, $B M F$ 1990;301:651-3.

2 British Thoracic Society, Research Unit of the Royal College of Physicians of London, King's Fund Centre, National Asthma Campaign. Guidelines for London, King's Fund Centre, National Asthma Campaign. Guidelines for
management of asthma in adults. II. Acute severe asthma. BMJ 1990;301: managem

3 International consensus report on diagnosis and treatment of asthma. Eur Respir 7 1992;5:601-41.

4 Sears MR, Taylor DR, Print CG, Lake DC, Qingqing L, Flannery EM, et al. Regular inhaled beta-agonist treatment in bronchial asthma. Lancet 1990; 336:1391-6.

5 Barnes PJ, Lee TH, Holgate S. Asthma therapy-present anxieties and future research. Adverse Drug Reaction Bulletin 1992;154:579-82.

6 Vathenen AS, Knox AJ, Higgins BG, Britton JR, Tattersfield AE. Rebound increase in bronchial responsiveness after treatment with inhaled terbutaline. Lancet 1988;i:554-8.

7 Peel ET, Gibson GJ. Effects of long-term inhaled salbutamol therapy on the provocation of asthma by histamines. Am Rev Respir Dis 1980;121:973-8.

8 van Schayck CP, Dompeling E, van Herwaarden CLA, Folgering H, Veerbeck ALM, van der Hoogen HJM, et al. Bronchodilator treatment in moderate ALM, van der Hoogen HJM, et al. Bronchodilator treatment in moderate
asthma or chronic bronchitis: continuous or on demand? A randomised asthma or chronic bronchitis: continuous
controlled study. BMf 1991;303:1426-31.

9 Hilton CJ, Fuller RW. Bronchodilator treatment in asthma: continuous or on demand? BMF 1992;304:121.

10 Pearce N, Crane J, Burgess C, Jackson R, Beasley R. Beta agonists and asthma mortality: déjà vu. Clin Exp Allergy 1991;21:401-10.

11 Spitzer WO, Suissa S, Emst P, Horwitz RI, Habbick B, Cockcroft D, et al. A nested case-control of the relationship between beta agonists and death and near-death from asthma. $N$ Engl $\mathcal{Y}$ Med (in press).

12 Zach MS, Karner U. Sudden death in asthma. Arch Dis Child 1989;64: 1446-51.

13 Dahl R, Earnshaw JS, Palmer JBD. Salmeterol: a four week study of a longacting beta-adrenoceptor agonist for the treatment of reversible airways disease. Eur Respir f 1991:4:1178-84.

14 Management of asthma in the community [editorial]. Lancet 1989;ii: 199-200.

15 Office of Health Economics. Asthma. London: OHE, 1990.
16 Waller PC, Wood SM, Langman MJS, Breckenridge AM, Rawlins MD. Review of company post-marketing studies. BMF 1992;304:1470-2.

(Accepted 28 fanuary 1993) 